\title{
Association between type 2 diabetes and cancer incidence in China: data in hospitalized patients from 2006 to 2013
}

\author{
Shan Lu' ${ }^{1 \#}$, Anzhi Wang ${ }^{2 \#}$, Shumei Miao ${ }^{3}$, Xin Zhang ${ }^{3}$, Shenqi Jing ${ }^{3}$, Tao Shan ${ }^{3}$, Yongan Guo ${ }^{2}$, Yun Liu ${ }^{3}$ \\ ${ }^{1}$ Health Education Section of the Outpatient Department, the First Affiliated Hospital, Nanjing Medical University, Nanjing 210029 , China; \\ ${ }^{2}$ Engineering Research Center of Health Service System Based on Ubiquitous Wireless Networks, Ministry of Education, Nanjing University of \\ Posts and Telecommunications, Nanjing 210023, China; ${ }^{3}$ Department of Information, the First Affiliated Hospital, Nanjing Medical University, \\ Nanjing 210029, China \\ Contributions: (I) Conception and design: S Lu, S Miao; (II) Administrative support: Y Liu, Y Guo; (III) Provision of study materials or patients: A \\ Wang, X Zhang; (IV) Collection and assembly of data: S Lu, A Wang; (V) Data analysis and interpretation: S Lu, S Miao; (VI) Manuscript writing: \\ All authors; (VII) Final approval of manuscript: All authors. \\ \#These authors contributed equally to this work. \\ Correspondence to: Yun Liu. Department of Geratology, the First Affiliated Hospital of Nanjing Medical University, No. 300 Guangzhou Rd., Gulou \\ District, Nanjing 210029, China. Email: liuyun@njmu.edu.cn.
}

Background: Evidence of a role for type 2 diabetes in overall cancer risk is limited in ethnic Chinese populations. We therefore investigated whether there is an association between diabetes and cancer incidence.

Methods: All type 2 diabetes and cancer hospitalized patients from the First Affiliated Hospital of Nanjing Medical University between 2006.01 and 2013.12 were eligible for the study. Our research used healthcare information technology and statistical methods to analyze the clinical data of hospitalized patients and explored the relationship between diabetes and cancer. Participants with fasting glucose $\geq 126 \mathrm{mg} / \mathrm{dL}$, or taking hypoglycemic medications, were classed as having type 2 diabetes. Cancer incidence was established through regular follow-up interviews and medical records. Data were entered into Excel and a database was set up with ACCESS software. Clinical information such as demographics like gender, age, occupation, marriage, insurance and etc., diagnoses, and prescription record were chosen and analyzed. SPSS software was also used for statistical analysis.

Results: The number of patients with both diabetes and cancer rose from 220 cases in 2006 to 1,623 cases in 2013. The proportion of cancer patients with diabetes has also increased every year. Younger participants (aged $\leq 50$ years) with diabetes had a greater risk of all cancers $[\mathrm{P}<0.005$, odds ratio $(\mathrm{OR})>3.4]$. And cancer patients with diabetes occurs more frequently in male patients than in female patients, especially since 2009 the proportion has increased more evidently $(\mathrm{P}<0.005$, OR $>1.4)$. Further analysis showed that the level of blood lipid in patients with diabetes mellitus and cancer was significantly different from that in patients with simple diabetes mellitus $(\mathrm{P}<0.05)$.

Conclusions: Our results clearly demonstrate a positive association between diabetes and cancer, especially in younger individuals aged less than 50 years. This finding highlights a need for greater awareness among public health workers and physicians of the importance of effective control of diabetes in the younger population.

Keywords: Diabetes; cancer incidence; big data; statistical analysis

Submitted Oct 18, 2019. Accepted for publication Jan 10, 2020.

doi: 10.21037/atm.2020.01.101

View this article at: http://dx.doi.org/10.21037/atm.2020.01.101 


\section{Introduction}

With the economic development, lifestyle changes, the increase of environmental pollution and many other factors, the incidence of diabetes has been increasing in the past few decades. Currently, diabetes mellitus has become a very popular and worldwide health issue. From the WHO statistics, it is estimated that 171 million patients in the year of 2000 will increase to about 366 million by the year of 2030 (1). Meanwhile, the neoplastic incidence has been increasing too and as a result, cancer has become one of the leading diseases which can cause death in the world. Therefore, diabetes and cancer have become two major chronic diseases that could impact human health seriously $(2,3)$. In the past few decades, Maynard and Wilson have presented that there was positive relationship between the incidence of diabetes and cancer $(4,5)$. And the American Diabetes Association (ADA) and the American Cancer Society (ACS) have released the statement together in 2010 that the patients with diabetes have high risk of cancer and the cancer prognosis will be affected as well $(6,7)$. More, lots of studies at home and abroad have found the etiological relationship between diabetes and cancer that the incidence of malignant tumors has been increasing significantly in the diabetes patients.

There is some relationship between cancer and the overeating. For diabetes patients, when lacking of insulin and when the metabolism of sugar, protein and fat are imbalanced, many problems will come out accordingly and they will affect their life quality seriously. The unhealthy lifestyle can lead to the dyslipidemia too which is also one of the reasons to cause the diabetes with cancer. When the patients suffer from both diabetes and cancer, the two diseases will impact each other. As a result, the prognosis will be affected and the health will be deteriorated. Therefore, for the patients with both diabetes and cancer have gained more and more research attention now.

There is a prediction by International Data Corporation (IDC) that the big data market in China will realize fivefold increase from 2012 to 2016. Based on these data, government, healthcare, banking, telecommunications and other industries hold the largest share. Because of the rapid development of health information, the types and size of the medical data are growing greatly and unprecedentedly and the health sector has ushered in the era of big data. The capacity of hospital information databases has been expanding because of the wide application of the information system and digitized medical apparatus in medical institutions. These hospital information resources are very valuable and vital to manage and control the disease and medical research. Taking good use of these information resources in a better and effective way is to give service to the management, treatment, research and teaching in healthcare which has been a main focus in current researches $(8,9)$.

In this paper, we applied the information technology and the related statistical knowledge into the analysis of the clinical data for the hospitalized patients between January 2006 and December 2013. Therefore, the statistical characteristics and the relationship between diabetes and cancer were able to be analyzed. Based on preliminary research of the clinical big data, the statistical evidence for researchers of diabetes and cancer could be provided to the relevant sectors to improve the public health.

\section{Methods}

\section{Resources}

Our research got the approval from Ethics Committee of the First Affiliated Hospital of Nanjing Medical University (2013-SRFA-139, Jiangsu Province Hospital). The hospitalized patients between January 2006 and December 2013 were selected to be the research objects and data of all these patients were from the Medical Records System (MRS) and the Hospital Information System (HIS) in the First Affiliated Hospital of Nanjing Medical University (Jiangsu Province Hospital). More, all the records and information of the patients were all anonymized and de-identified.

\section{Disease classification}

Based on the ICD-10 (10) we used the professional medical record coders to code the discharge diagnoses. With the primary diagnosis and other valuable diagnoses, a clinical database was launched to classify the diseases into different types and the number of the patients with each disease was calculated too. The diabetes and cancer patients were our main focus of our research. Meanwhile, the primary diagnosis and other eight diagnoses from HIS were analyzed too.

\section{Statistical methods}

All data was put into Excel for further analysis by means of an ACCESS software in a database developed by Microsoft Company. The key valuable information was extracted via SQL language. After that, in order to analyze all the statistics, the SPSS software was applied into the extraction 
Table 1 The analysis of diabetes patients from 2006 to 2013

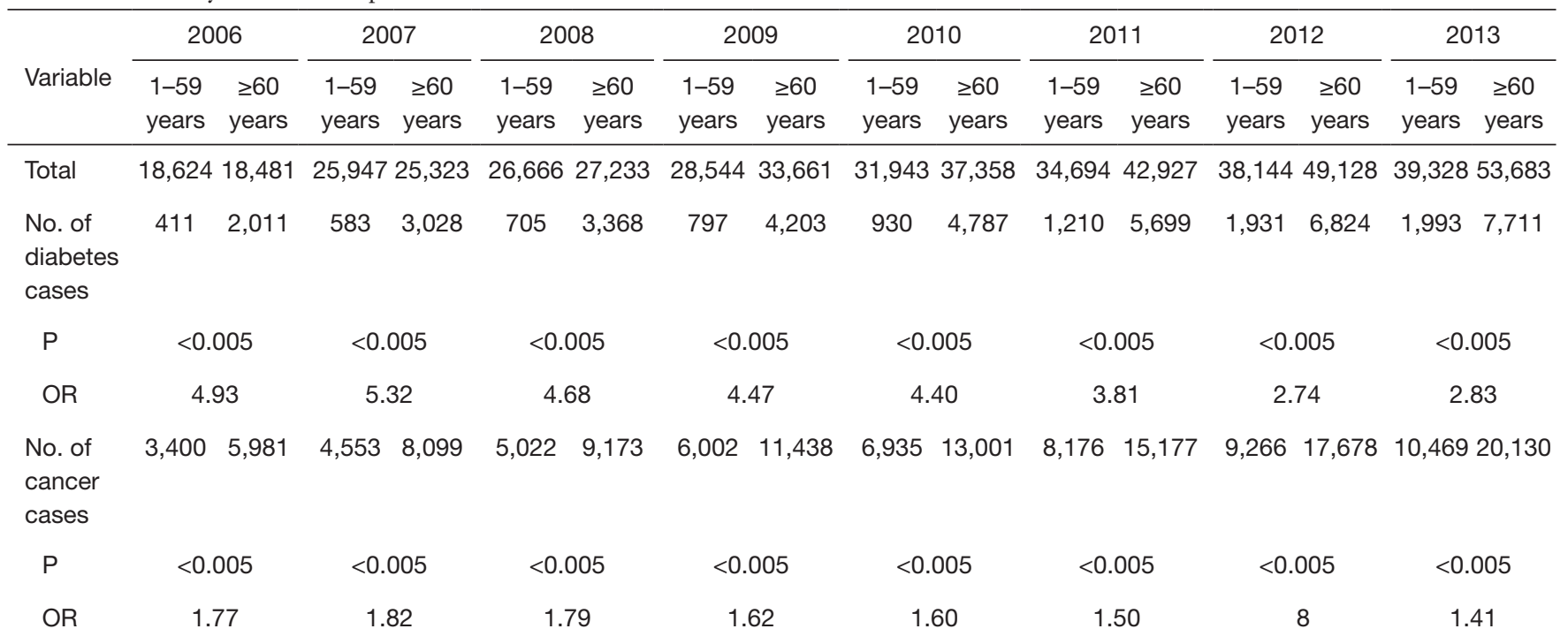

OR, odds ratio.

of the crucial information which is a very mature tool in analyzing statistics. We used $\mathrm{P}$ value and $\mathrm{OR}$ value to analyze the relationship between diabetes and cancer in our research. P values was calculated via the chi-square calibration equation as follow:

$$
\chi^{2}=\sum \frac{\left(f_{0}-f_{e}\right)^{2}}{f_{e}} \sim \chi^{2}(\mathrm{df})
$$

$\mathrm{P}$ values were from the $\chi^{2}$ table from where we got the actual observation number $f_{0}$ and the theoretical number $f_{\mathrm{e}}$. The factor analysis was very different when $\mathrm{P}$ was less than 0.005 . The comparison differences were shown to be statistically significant when the $\mathrm{P}$ value was less than 0.01 whereas the comparison difference was not statistically significant when $\mathrm{P}$ was larger than 0.05 .

We calculated the OR value as:

$\mathrm{OR}=\mathrm{ad} / \mathrm{bc}(\mathrm{OR} \geq 3$ was defined as meaningful $)$

OR means the odds ratio, the indicators of disease related to the risk factors described in a case-controlled study. If OR was $\geq 3$, this indicated a high correlation to the disease.

\section{Results}

\section{Research overview}

From the year of 2016 to $2013,531,718$ patients were discharged from our hospital in total with 66,465 patients discharged every year. Women took 50.64\% among all the discharged patients. The number of discharged patients increased every year which was only 37,105 in 2006 but reached to 93,040 in 2013.

In 2013, cardiovascular diseases, normal delivery, chemotherapy, malignant tumors, pulmonary infection, type 2 diabetes, cataract, chronic renal failure, colon polyps and other specified medical care were ranked as the top 10 diseases in our hospital. Cancer and type 2 diabetes were among them. Their risk factors were in common like age, high body weight index, lack of physical activity, excessive intake of carbohydrates, abdominal obesity, sedentary lifestyle, alcohol consumption and smoking (11). In this paper, we used the data over the past 7 years to analyze the statistics which was valuable and helpful to identify the shared features and to explore the relationship between cancer patients and diabetes patients.

\section{The general distribution of diabetes}

During the 7 years, the number of diabetes patients increased every year from 2,422 in 2006 to 9,704 in 2013. From the data in Table 1, it shows that the elder group patients took the majority from 2006 to 2011 rather than non-elderly group. It was a significant difference in age $(\mathrm{P}<0.005, \mathrm{OR}>3)$, which indicates that there is very positive relationship between diabetes and age. And there was also big difference in age from 2012 to $2013(\mathrm{P}<0.005$, OR >2). 
Table 2 Baseline characteristics of diabetes and diabetes with cancer patients of hospitalized patients from 2006 to 2013

\begin{tabular}{|c|c|c|c|}
\hline Characteristics & $\mathrm{DM}(\mathrm{N}=46,191)$ & DM \& cancer $(\mathrm{N}=6,001)$ & $P$ value \\
\hline Age, mean (years) & 63.2 & 65.5 & $<0.005$ \\
\hline Married status, N (\%) & & & 0.15 \\
\hline Married & 44,277 (95.9) & $5,915(98.6)$ & \\
\hline Divorced or widowed & $647(1.4)$ & $647(10.8)$ & \\
\hline Medical insurance, N (\%) & & & $<0.005$ \\
\hline Rural cooperative insurance & $16,391(35.5)$ & $1,948(32.5)$ & \\
\hline Urban resident insurance & $17,302(37.5)$ & $2,089(34.8)$ & \\
\hline
\end{tabular}

DM, diabetes mellitus.

From this, it was found that non-elderly group patients suffering from diabetes were increasing every year. And it is the same conclusion as that in Yang Wenying's research in 2010 (12). With the rapid urbanization and the unhealthy dietary intake, the risk of diabetes was becoming more and more and the health of young people had been threatened as a result.

\section{The general distribution of cancer}

From 2016 to 2013, there were more and more cancer patients every year from 9,381 in 2006 to 30,599 in 2013. The cancer incidence increased too accordingly. Data in Table 1 shows that most of the patients who suffered from cancer during the year of 2006 to 2011 were elderly group people. It was a significant difference in age $(\mathrm{P}<0.005$, OR >1.4), indicating that there was positive relationship between cancer and age. Cancer is a disease which happens most in old people. However, compared with diabetes patients, the onset age of cancer was older. Recent years, it was found that OR value decreased, indicating that the onset age of tumors was growing in advance. All these results rightly matched with the phenomena of the onset of early diabetes. And the unhealthy diet is also an important reason to cause this disease (13-15).

\section{The general distribution of diabetes with cancer}

Age, economic development, lifestyle and environment are the related factors to cause the occurrence of diabetes and cancer (16). In order to analyze the diabetes and cancer, we applied the hospitalization data on the primary diagnosis together with other diagnoses. Based on these data, it was found that the patients with both diabetes and cancer became more and more from 220 in 2006 to 1,623 in 2013. And the cancer patients with diabetes increased every year too. The baseline characteristics of diabetes and diabetes with cancer patients of hospitalized patients from 2006 to 2013 was shown clearly in Table 2. From the gender, age, marital status and health insurance, we can see that they have had an impact to cause the incidence of cancer in the population of diabetes. From Table 3, the cases number of diabetes patients, cancer patients and patients with both diseases from 2006 to 2013 can be referred. From the ratio between the cases and the total case number of hospitalization, it can be found that the trend is ascending. The ascending rate has been more clear since 2010. From Table 4, you can refer to the data of cancer incidence in diabetic patients. It increased from $9.08 \%$ (the number of diabetes patients is 2,422 , while the number of patients with both diabetes and cancer is 220 in 2006) in 2006 to $16.72 \%$ in 2013 (the number of diabetes patients is 9,704 , while the number of patients with both diabetes and cancer is 1,623 in 2013). Compared with the cancer incidence in the general population of $0.29 \%$ ( 286 cases per 100,000 persons) announced in 2013, cancer incidence in diabetes patients was very higher, therefore it is very worthy to further explore the relationship between cancer and diabetes. 
Table 3 The gender analysis of diabetes with cancer patients from 2006 to 2013

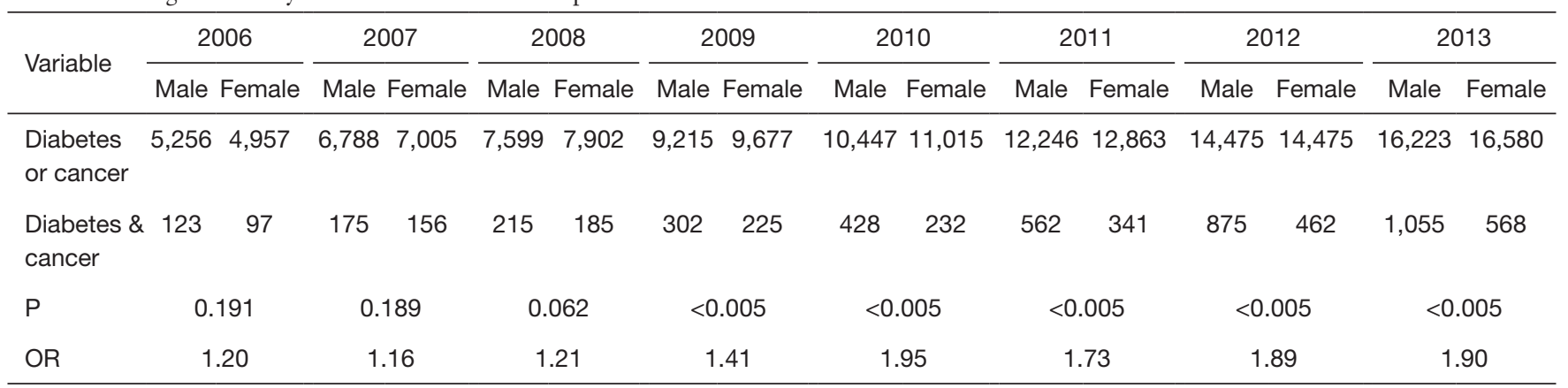

OR, odds ratio.

Table 4 The age analysis of diabetes with cancer patients from 2006 to 2013

\begin{tabular}{|c|c|c|c|c|c|c|c|c|c|c|c|c|c|c|c|c|}
\hline Variable & \multicolumn{2}{|c|}{2006} & \multicolumn{2}{|c|}{2007} & \multicolumn{2}{|c|}{2008} & \multicolumn{2}{|c|}{2009} & \multicolumn{2}{|c|}{2010} & \multicolumn{2}{|c|}{2011} & \multicolumn{2}{|c|}{2012} & \multicolumn{2}{|c|}{2013} \\
\hline Diabetes & 411 & 2,011 & 583 & 3,028 & 705 & 3,368 & 797 & 4,203 & 930 & 4,787 & 1,210 & 5,699 & 1,931 & 6,824 & 1,993 & 7,711 \\
\hline$P$ & \multicolumn{2}{|c|}{$<0.005$} & \multicolumn{2}{|c|}{$<0.005$} & \multicolumn{2}{|c|}{$<0.005$} & \multicolumn{2}{|c|}{$<0.005$} & \multicolumn{2}{|c|}{$<0.005$} & \multicolumn{2}{|c|}{$<0.005$} & \multicolumn{2}{|c|}{$<0.005$} & \multicolumn{2}{|c|}{$<0.005$} \\
\hline OR & \multicolumn{2}{|c|}{7.11} & \multicolumn{2}{|c|}{3.48} & \multicolumn{2}{|c|}{4.48} & \multicolumn{2}{|c|}{5.79} & \multicolumn{2}{|c|}{6.04} & \multicolumn{2}{|c|}{4.80} & \multicolumn{2}{|c|}{5.39} & \multicolumn{2}{|c|}{6.08} \\
\hline
\end{tabular}

OR, odds ratio.

\section{The age distribution of patients with diabetes and cancer}

Figure 1 shows the age distribution of cancer patients with diabetes. The horizontal axis represents the year and the vertical axis represents the annual discharges of all ages. Age is classified into three categories: below 41 years old, between 41 and 60 years old and above 60 years old. It was very common for the elderly patients to suffer from both cancer and diabetes. Since 2010, patients below 41 years old and between 41 to 60 years old increased year by year, indicating that more and more younger people were suffering from the both two diseases (17). From Figure 1, the incidence rate of cancer for diabetes patients in different age groups can be calculated. Most of the diabetic patients were over 60 years with high incidence of cancers and the cancer incidence rate in the elderly group patients increased significantly, especially in recent years. It was a significant difference in age in Table $4(\mathrm{P}<0.005$, OR $>3.4$ ) which showed more clearly that age could impact the

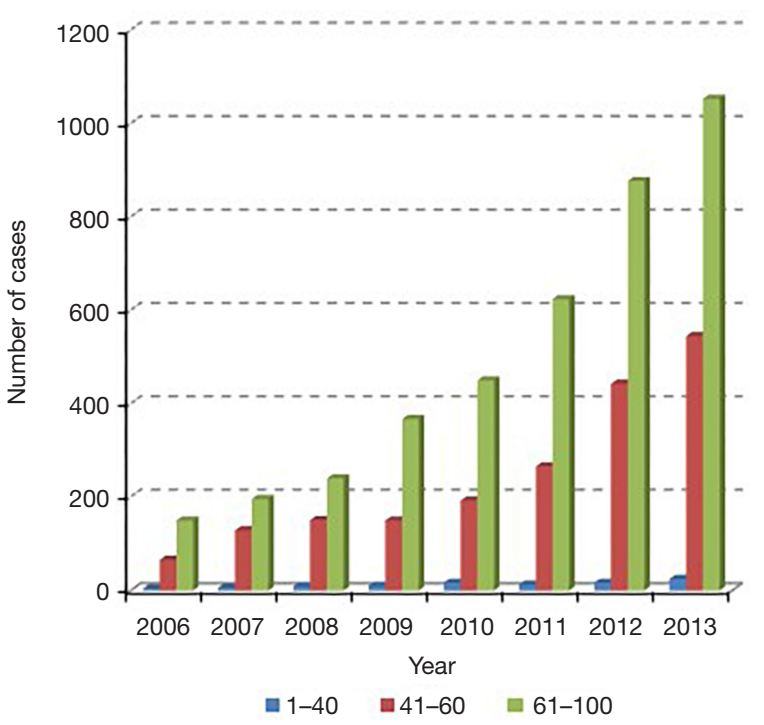

Figure 1 The age distribution of diabetes with cancer patients. 


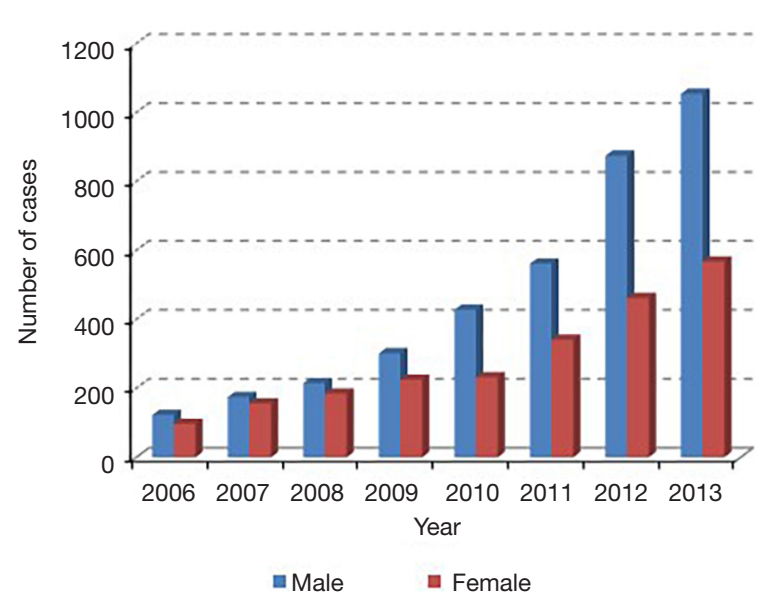

Figure 2 The gender distribution of diabetes with cancer patients.

incidence of cancer for diabetic patients. Therefore, early detection and intervention in daily life were suggested to be paid more attention. It is very important for people to have a healthy lifestyle. Reducing blood sugar levels to prevent diabetes and high vigilance in the detection of the onset of cancer are very necessary in life $(18,19)$.

\section{The gender distribution of patients with diabetes and cancer}

Figure 2 shows the gender distribution of diabetes with cancer patients. It indicates that male cancer patients with diabetes were more than female and this trend has increased more obviously in recent years. From Table 3, it indicates only a slight difference in gender before 2009 ( $P>0.05$, OR $<1.3)$. However, since 2009 , it is found that there is close relationship between gender $(\mathrm{P}<0.005, \mathrm{OR}>1.4)$ and cancer in diabetes patients. In recent years, Gender differences plays a more and more important role in occurrence of cancer. It maybe because that the male patients are more likely to have taste diet, to smoke, to drink and to have other bad habits. With the improvement of the living standard, these bad habits were even worse.

\section{Cancer types of different gender with diabetes}

We selected the patients with both diabetes and cancer to analyze the cancer types with different genders. In Table 5, the top five cancer diseases for male diabetes patients and female diabetes patients are listed respectively. Liver cancer ranks the top 1 for male diabetes patients while breast cancer and uterine cancer are the top 2 for female diabetes patients $(20,21)$.

\section{Clinical characteristics of diabetes complicated with gastrointestinal tumors}

The general information of diabetes with gastrointestinal tumors is shown in Table 6. From the independent sample test result, it was found that compared with the patients with simple diabetes, the levels of cholesterol (Table 7), triglyceride and low-density lipoprotein cholesterol in patients with type 2 diabetes mellitus complicated with gastrointestinal cancer were lower with statistically significant difference. However, the level of high-density lipoprotein was higher with statistically significant difference too. It was found that there was a significant difference between the blood lipid level of diabetic patients with gastrointestinal tumor and that of diabetic patients with other tumors, and the relationship between the cholesterol level and the incidence of diabetic gastrointestinal tumor was U-shaped (Table 8, Figure 3).

\section{Average daily cost}

Based on the data in Figure 4, the average daily cost increased every year in the past 7 years. The cost also increased for diabetes patients, consistent with the increased average cost of hospitalization. Generally, compared with other patients, the average hospital costs for patients with diabetes and cancer are higher. Therefore, for diabetes patients, the cost burden will be heavier for them if they suffer from cancer at the same time.

\section{Discussion}

Most of the previous studies focused on the mechanism of diabetes and tumor, and few of the large-scale inpatient studies. In this study, the incidence of diabetes with different tumors in different gender and age groups was mainly analyzed. Through further research, it was found that the blood lipid level of diabetes with gastrointestinal tumor and that of diabetes with other tumors were the same. There were significant differences in lipid levels.

The rapid increase of the incidence and prevalence of diabetes and cancer make them as the two major diseases in the world currently, which is a great threaten to human health. In order to reduce the harm of the two chronic diseases, the relationship between diabetes and cancer has 
Table 5 The top five cancer disease for diabetes patients

\begin{tabular}{|c|c|c|c|c|c|c|c|c|c|}
\hline No. & Gender & 2006 & 2007 & 2008 & 2009 & 2010 & 2011 & 2012 & 2013 \\
\hline 1 & Female & $\begin{array}{l}\text { Breast } \\
\text { cancer }\end{array}$ & $\begin{array}{l}\text { Breast } \\
\text { cancer }\end{array}$ & $\begin{array}{l}\text { Uterine } \\
\text { fibroids }\end{array}$ & $\begin{array}{l}\text { Uterine } \\
\text { fibroids }\end{array}$ & $\begin{array}{l}\text { Uterine } \\
\text { fibroids }\end{array}$ & $\begin{array}{l}\text { Colorectal } \\
\text { cancer }\end{array}$ & $\begin{array}{l}\text { Gastric } \\
\text { cancer }\end{array}$ & $\begin{array}{l}\text { Colorectal } \\
\text { cancer }\end{array}$ \\
\hline 2 & Female & $\begin{array}{c}\text { Pancreatic } \\
\text { cancer }\end{array}$ & $\begin{array}{l}\text { Uterine } \\
\text { fibroids }\end{array}$ & $\begin{array}{l}\text { Breast } \\
\text { cancer }\end{array}$ & $\begin{array}{l}\text { Gastric } \\
\text { cancer }\end{array}$ & $\begin{array}{c}\text { Cardiac } \\
\text { adenocarcinoma }\end{array}$ & Lymphoma & $\begin{array}{l}\text { Hodgkin's } \\
\text { lymphoma }\end{array}$ & $\begin{array}{l}\text { Uterine } \\
\text { fibroids }\end{array}$ \\
\hline 3 & Male & $\begin{array}{l}\text { Gastric } \\
\text { cancer }\end{array}$ & $\begin{array}{c}\text { Non- } \\
\text { Hodgkin's } \\
\text { lymphoma }\end{array}$ & $\begin{array}{l}\text { Lung } \\
\text { cancer }\end{array}$ & $\begin{array}{l}\text { Colorectal } \\
\text { cancer }\end{array}$ & $\begin{array}{l}\text { Prostate } \\
\text { cancer }\end{array}$ & $\begin{array}{c}\text { Lung } \\
\text { adenocarcinoma }\end{array}$ & $\begin{array}{l}\text { Lung } \\
\text { cancer }\end{array}$ & $\begin{array}{c}\text { Esophageal } \\
\text { cancer }\end{array}$ \\
\hline \multirow[t]{2}{*}{4} & Male & $\begin{array}{l}\text { Prostate } \\
\text { cancer }\end{array}$ & $\begin{array}{l}\text { Lung } \\
\text { cancer }\end{array}$ & $\begin{array}{c}\text { Cardiac } \\
\text { adenocarcinoma }\end{array}$ & $\begin{array}{c}\text { Lung } \\
\text { adenocarcinoma }\end{array}$ & $\begin{array}{l}\text { Pancreatic } \\
\text { cancer }\end{array}$ & $\begin{array}{l}\text { Colon } \\
\text { cancer }\end{array}$ & $\begin{array}{l}\text { Prostate } \\
\text { cancer }\end{array}$ & $\begin{array}{c}\text { Pancreatic } \\
\text { cancer }\end{array}$ \\
\hline & Female & $\begin{array}{l}\text { Bladder } \\
\text { cancer }\end{array}$ & $\begin{array}{l}\text { Pancreatic } \\
\text { cancer }\end{array}$ & $\begin{array}{c}\text { Liver } \\
\text { cancer }\end{array}$ & $\begin{array}{l}\text { Lung } \\
\text { cancer }\end{array}$ & $\begin{array}{l}\text { Pancreatic } \\
\text { cancer }\end{array}$ & $\begin{array}{l}\text { Hodgkin's } \\
\text { lymphoma }\end{array}$ & $\begin{array}{l}\text { Colorectal } \\
\text { cancer }\end{array}$ & $\begin{array}{l}\text { Lung } \\
\text { cancer }\end{array}$ \\
\hline \multirow[t]{2}{*}{5} & Male & $\begin{array}{l}\text { Lung } \\
\text { cancer }\end{array}$ & $\begin{array}{l}\text { Gastric } \\
\text { cancer }\end{array}$ & $\begin{array}{l}\text { Gastric } \\
\text { cancer }\end{array}$ & $\begin{array}{l}\text { Gastric } \\
\text { cancer }\end{array}$ & $\begin{array}{l}\text { Colorectal } \\
\text { cancer }\end{array}$ & $\begin{array}{l}\text { Prostate } \\
\text { cancer }\end{array}$ & $\begin{array}{l}\text { Gastric } \\
\text { cancer }\end{array}$ & $\begin{array}{l}\text { Colorectal } \\
\text { cancer }\end{array}$ \\
\hline & Female & $\begin{array}{l}\text { Multiple } \\
\text { myeloma }\end{array}$ & $\begin{array}{l}\text { Ovarian } \\
\text { cancer }\end{array}$ & $\begin{array}{l}\text { Gastric } \\
\text { cancer }\end{array}$ & $\begin{array}{l}\text { Pancreatic } \\
\text { cancer }\end{array}$ & $\begin{array}{l}\text { Colorectal } \\
\text { cancer }\end{array}$ & $\begin{array}{c}\text { Cardiac } \\
\text { adenocarcinoma }\end{array}$ & $\begin{array}{l}\text { Ovarian } \\
\text { cancer }\end{array}$ & $\begin{array}{c}\text { Pancreatic } \\
\text { cancer }\end{array}$ \\
\hline
\end{tabular}

getting more attention from the public health researchers and epidemiologists. There are lots of studies indicating that diabetes is able to impact the presence of cancer cells (22). There are also lots of studies indicating that the biological effects of diabetes can cause the increase the risk of cancer (23-25). Firstly, diabetic patients with hyperinsulinemia have high cancer risk because hyperinsulinemia is mitogenic which can promote the development of malignant tumor cells. Apoptosis of the stem cells promotes the development of cancer. And hyperinsulinemia is common in type 2 diabetic patients, which may be caused by endogenous insulin resistance, exogenous insulin injection or increased insulin secretion. Insulin binds to insulin receptor, activates insulin receptor substrate-1 (IRS-1) and downstream mitogen activated protein kinase (MAPK), phosphoinositide-3 kinase/Akt (PI3K/Akt) and Janus kinase/transcription factor and transcription activator (JAK/ STAT) pathways, which can promote cell proliferation and protein synthesis and inhibit cell proliferation. Insulin resistance refers to the impairment of the function of insulin in peripheral target tissue, which leads to the increase of insulin level in blood. In type 2 diabetic patients, insulin resistance and hyperinsulinemia often exist at the same time, so in the occurrence of cancer and the risk of death and other aspects, insulin resistance and hyperinsulinemia may have a coordinated role in promoting, directly or indirectly, tumor proliferation, invasion and migration. Secondly, patients with type 2 diabetes usually have the oxidative stress which also can impact the mechanisms of the malignant cells. There are some vitro studies which have explained that the insulin-like growth factor (IGF-1) and insulin can have impact on some cancers like prostate cancer, lung cancer and breast cancer issues (26).

In this paper, we analyzed the clinical data for the hospitalized patients from the year of 2006 to 2013 including 46,191 cases of diabetes and 6,001 cases with diabetes and cancer. There were more and more patients suffered from diabetes and cancer respectively in recent years. Therefore, the number of patients with both of the two diseases increased too. Both of the two diseases have close relationship with age. As people grow older, more and more patients suffer from both of the two diseases. Obviously, 
Table 6 Basic/clinical characteristics of study participants $(\mathrm{x} \pm \mathrm{s})$

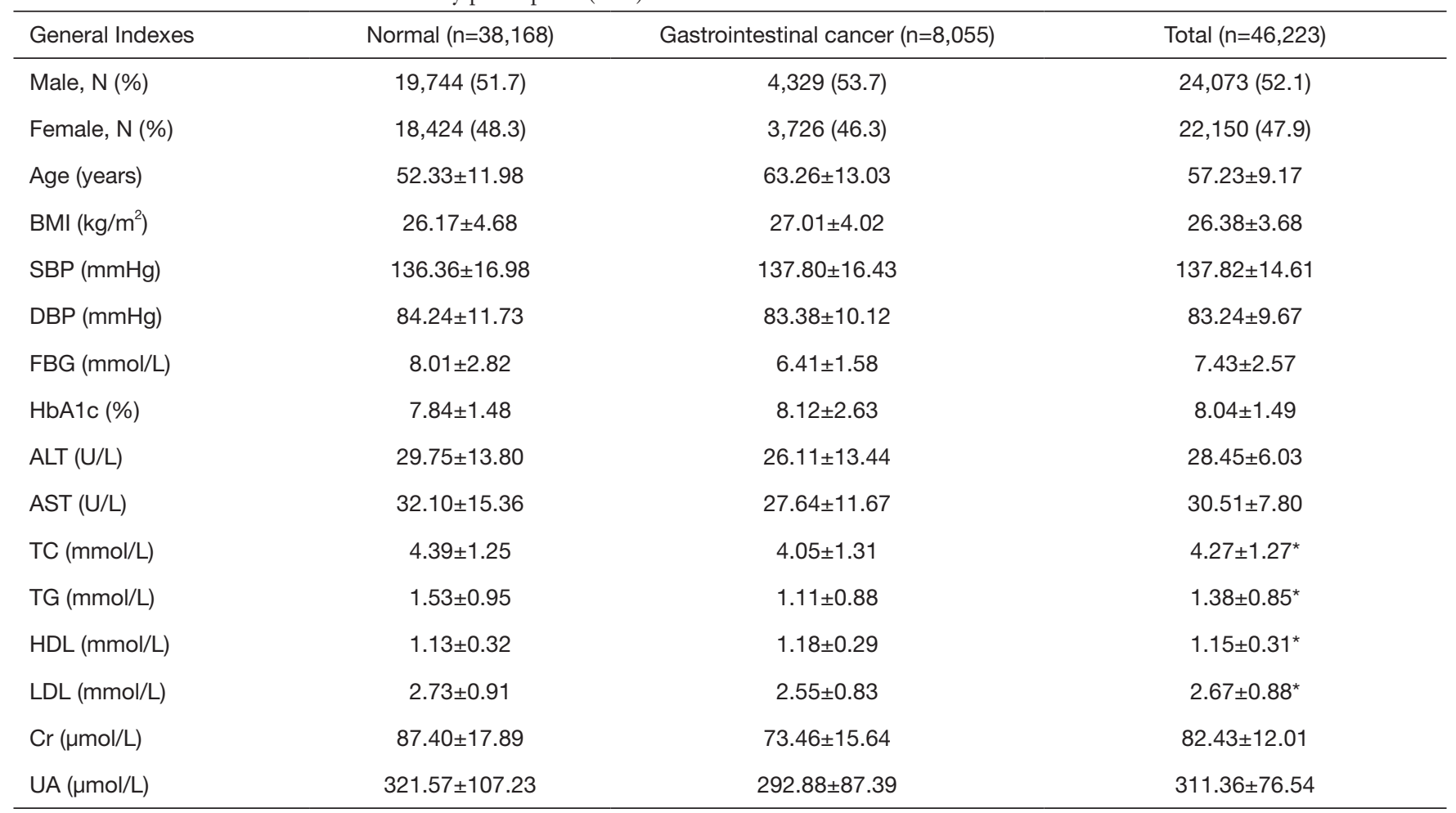

* $\mathrm{P}<0.001$ was considered as statistically significant difference. BMI, body mass index; SBP, systolic blood pressure; DBP, diastolic blood pressure; FBG, fasting blood glucose; HbA1c, glycosylated hemoglobin; ALT, glutamic-pyruvic transaminase; AST, glutamic oxalacetic transaminase; TC, total cholesterol; TG, triglycerides; HDL, high density lipoprotein; LDL, low density lipoprotein; Cr, creatinine; UA, uric acid.

Table 7 The comparison of blood lipids between normal and gastrointestinal cancer groups

\begin{tabular}{lcccc}
\hline General Indexes & Normal & Gastrointestinal cancer & $t$ & 17.69 \\
\hline TC $(\mathrm{mmol} / \mathrm{L})$ & $4.39 \pm 1.25$ & $4.05 \pm 1.31$ & 27.77 & $0.000^{*}$ \\
$\mathrm{TG}(\mathrm{mmol} / \mathrm{L})$ & $1.53 \pm 0.95$ & $1.11 \pm 0.88$ & 14.29 & $0.000^{*}$ \\
$\mathrm{HDL}(\mathrm{mmol} / \mathrm{L})$ & $1.13 \pm 0.32$ & $1.18 \pm 0.29$ & 14.64 & $0.000^{*}$ \\
LDL $(\mathrm{mmol} / \mathrm{L})$ & $2.73 \pm 0.91$ & $2.55 \pm 0.83$ & $0.000^{*}$ \\
\hline
\end{tabular}

The $t$-test with different samples was adopted for comparison between groups. ${ }^{*}, \mathrm{P}<0.001$ was considered as statistically significant difference. TC, total cholesterol; TG, triglycerides; HDL, high density lipoprotein; LDL, low density lipoprotein.

the number of diabetes and cancer over 50 years old increased a lot and age is an important factor. Meanwhile, based on the statistical analysis, it showed that the nonelderly group patients with these two diseases became more and more every year. It rightly matches the findings by Yang Wenying. The unhealthy diet and rapid urbanization let the two chronic diseases become prevalent in younger people.

In terms of gender, the number of male patients with the two diseases was more than female patients. Based on the analysis of diabetes with cancer patients, male patients are more likely to have the liver cancer because they have not good lifestyle such as drinking, smoking and other bad habits which will have a direct impact on this disease. And female patients are more likely to suffer from the uterine fibroids and breast cancer. The identity of gender also accounts for the impact of diabetes on sex hormones.

Some studies have shown that type 2 diabetes mellitus is an independent risk factor for the progression of bladder 
Table 8 Number of patients with simple diabetes with different total cholesterol ranges and number of diabetic patients with gastrointestinal tumors

\begin{tabular}{lcc}
\hline $\mathrm{TC}(\mathrm{mmol} / \mathrm{L})$ & Patients & Patients with malignant tumors \\
\hline $\mathrm{TC} \leq 1$ & 57 & 20 \\
$1<\mathrm{TC} \leq 2$ & 693 & 205 \\
$2<\mathrm{TC} \leq 3$ & 3,873 & 951 \\
$3<\mathrm{TC} \leq 4$ & 10,759 & 2,393 \\
$4<\mathrm{TC} \leq 5$ & 12,123 & 2,426 \\
$5<\mathrm{TC} \leq 6$ & 6,539 & 1,274 \\
$6<\mathrm{TC} \leq 7$ & 3,290 & 600 \\
$7<\mathrm{TC} \leq 8$ & 499 & 95 \\
$8<\mathrm{TC} \leq 9$ & 153 & 33 \\
$9<\mathrm{TC} \leq 10$ & 71 & 18 \\
$10<\mathrm{TC} \leq 11$ & 38 & 12 \\
$\mathrm{TC}>11$ & 73 & 28 \\
\hline
\end{tabular}

Chi-square test: $P=0.000$. TC, total cholesterol.

cancer, which is closely related to the prognosis of patients. Diabetes mellitus is associated with a higher risk of bladder cancer in men. There is a great controversy about the relationship between diabetes and prostate cancer. Some researches think that prostate cancer is the only cancer negatively related to diabetes. It is found that the risk of prostate cancer is reduced by $10-20 \%$ in diabetic patients, which may be related to the decrease of testosterone level caused by high glucose. However, there are also studies that suggest that the risk of prostate cancer and its malignancy are significantly increased in patients with diabetes. Further discussion is needed to determine whether this dispute is affected by bias or the course and severity of diabetes. And long-term bad eating habits are easy to cause cancer of digestive tract. For example, studies have suggested that eating irregular, eating fast, overeating, eating leftovers and other habits are risk factors of gastric cancer. In addition, a large number of studies have confirmed that high salt diet is related to the increased incidence and mortality of gastric cancer. Studies also show that the mortality of gastric cancer is significantly related to sodium and nitrate, but the relationship with the former is stronger. For colorectal cancer, many studies have shown that a Western-style diet characterized by a large amount of meat, fat, sugar and sweets can increase the risk of morbidity, but also increase the risk of diabetes. Meanwhile, it has been confirmed

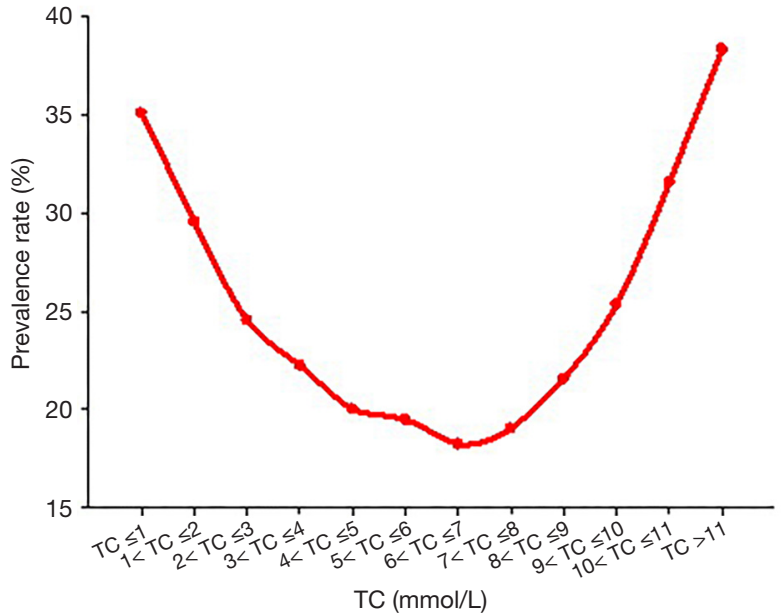

Figure 3 The correlation curve between total cholesterol level and gastrointestinal cancer prevalence in DM patients. DM, diabetes mellitus.

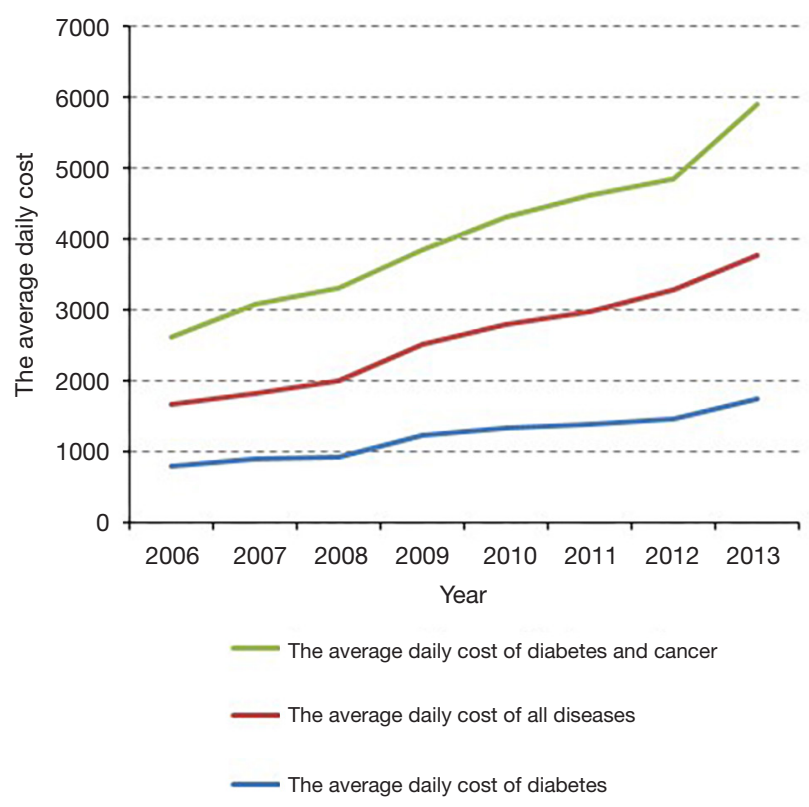

Figure 4 The average daily cost of hospitalization.

epidemiologically that obesity, insulin resistance state (i.e., metabolic syndrome, polycystic ovary syndrome) and diabetes have increased the incidence of cancer significantly. As long as the diabetic disease is confirmed, the patients will be also suggested to take regular inspections and medical examinations to check the risk of liver cancer, colorectal cancer, uterine cancer, breast cancer and other related cancers, so that cancer could be detected and intervened 
early. It is a complex process before the occurrence of cancer which usually takes a very long time and it is also impacted by many factors. In our study, it is very different level of blood lipid in patients with diabetes mellitus and in patients with both diabetes and cancer. It may have something to do with lipid metabolism taking part in multiple cellular processes including growth, proliferation, differentiation, apoptosis, inflammation, movement and membrane stability. Meanwhile, it is suggested to observe the level of blood lipids in these patients dynamically and to maintain it in the optimum range to assess their condition and risk of digestive tract tumors. In the follow-up studies, it is suggested to cover more research objects like the type of diabetes, duration of treatment, the degree of control, etc.

In terms of economy, with the improvement of living standard and the increase of labor costs, the hospital cost has increased. Because of the technological development, the emergence of various new medical instruments and the increasing healthcare demands, the average cost for each patient has increased accordingly. The financial burden for diabetic patients has increased every year and therefore it becomes more difficult for patients with both diabetes and cancer. Nowadays, in order to avoid the deterioration of serious disease, lots of highly effective interventions are used, including prevention screening for the whole population and personal interventions. It is advisable and convenient for people to detect and intervene the diseases as early as we can in our daily life. In order to reduce blood sugar and to prevent diabetes, a healthy lifestyle should be actively recommended and the vigilance of cancer genesis should be improved much too.

With the development of healthcare information technology, large amounts of medical information data have been accumulated which will be sure to be a great impact on medicine, teaching and research. The construction of data exchange platforms and clinical data repositories have become the superiority in the development of information technology which can assist the clinical decisions and scientific research. In this paper, through the analysis of the 8-year hospitalization data in the First Affiliated Hospital of Nanjing Medical University, the relationship between cancer disease and diabetes disease is able to be analyzed. Firstly, the data warehouse of diabetes and cancer is established to analyze all the data. Then the clinical big data is applied in the clinical medical research. As the development of medical information systems, a large amount of data has already been accumulated. The healthcare reform can be promoted through information technology by fully exploiting big data in medicine to support clinical research and by improving the quality of medical management.

\section{Conclusions}

With the help of all statistics, this research is able to present the positive relationship between diabetes and cancer successfully. The younger individuals below 50 years old are the main research objects among all Chinese population. In addition, many factors like gender and insurance type also contribute to the positive effect in different degrees. Cancer patients with diabetes occur more frequently in male patients than in female patients. Compared with the diabetes patients with more complete insurance, diabetes patients without insurance are more likely to suffer from cancer disease. This finding proposes that to remind the public health workers and physicians to control the diabetes effectively in younger people is very urgent and important. More, it is very important for women to pay more attention to set up a healthy lifestyle by giving up bad eating habits. What is really important is that we need to call for a promotion of the comprehensive health policy to improve the public health and to reduce the risk of cancer for diabetic patients.

\section{Acknowledgments}

Funding: The present study was supported by grants from the National Key Research \& Development Plan of Ministry of Science and Technology of the People's Republic of China (No. 2018YFC1314900, 2018YFC1314901), the 2016 industry prospecting and common key technology key projects of Jiangsu Province Science and Technology Department (No. BE2016002-4), the 2016 projects of Nanjing Science Bureau (No. 201608003), the 2017 projects of Jiangsu Provincial Department of Finance (No. 2150510), the 2018 project of Jiangsu Committee of Health (No. H2018071).

\section{Footnote}

Conflicts of Interest: The authors have no conflicts of interest to declare.

Ethical Statement: The authors are accountable for all aspects of the work in ensuring that questions related to the accuracy or integrity of any part of the work are appropriately investigated and resolved. This work was approved by the Ethics Committee of the First Affiliated Hospital of Nanjing Medical University (2013-SRFA-139, 
Jiangsu Province Hospital).

Open Access Statement: This is an Open Access article distributed in accordance with the Creative Commons Attribution-NonCommercial-NoDerivs 4.0 International License (CC BY-NC-ND 4.0), which permits the noncommercial replication and distribution of the article with the strict proviso that no changes or edits are made and the original work is properly cited (including links to both the formal publication through the relevant DOI and the license). See: https://creativecommons.org/licenses/by-nc-nd/4.0/.

\section{References}

1. Shikata K, Ninomiya T, Kiyohara Y. Diabetes mellitus and cancer risk: review of the epidemiological evidence. Cancer Sci 2013;104:9-14.

2. Liu Y, Yang G, Zeng Y, et al. Policy Dialogue on China's Changing Burden of Disease. Lancet 2013;381:1961-2.

3. Yang G, Wang Y, Zeng Y, et al. Rapid health transition in China, 1990-2010: findings from the Global Burden of Disease Study 2010. Lancet 2013;381:1987-2015.

4. Maynard GD. A Statistical Study in Cancer Death-Rates. Biometrika 1910;7:276-304.

5. Wilson EB, Maher HC. Cancer and tuberculosis with some comments on cancer and other diseases. Am J Cancer 1932;16:227-50.

6. Giovannucci E, Harlan DM, Archer MC, et al. Diabetes and cancer: a consensus report. CA Cancer J Clin 2010;60:207-21.

7. Wan GL, Wu SG, Wei KX. Correlation between malignant tumors and diabetes mellitus. Med J Qilu 2005;20:478-80.

8. Gao HS, Xiao L, Xu DW et al. Medical data mining platform based on cloud computing. Journal of Medical Informatics 2013;34:7-12.

9. Cai J, Zhang T, Zong W. Challenges and Considerations of the Big Data of Medicine. Chinese Journal of Health Informatics and Management 2013;10:292-5.

10. World Health Organization, ICD-10, vol. 2. 2nd edition. Geneva, Switzerland: World Health Organization, 2005.

11. Wang H, Dwyer-Lindgren L, Lofgren KT, et al. Agespecific and sex-specific mortality in 187 countries, 19702010: a systematic analysis for the Global Burden of Disease Study 2010. Lancet 2012;380:2071-94.

12. Yang $\mathrm{W}, \mathrm{Lu} \mathrm{J}$, Weng $\mathrm{J}$, et al. Prevalence of diabetes among men and women in China. N Engl J Med 2010;362:1090-101.

13. Bener A, Al-Laftah F, Al-Hamaq AO, et al. A study of diabetes complications in an endogamous population: an emerging public health burden. Diabetes Metab Syndr 2014;8:108-14.

14. Bray F, Jemal A, Grey N, et al. Global cancer transitions according to the Human Development Index (2008-2030): a population-based study. Lancet Oncol 2012;13:790-801.

15. Traebert J, Schneider IJ, Colussi CF, et al. Burden of disease due to cancer in a Southern Brazilian state. Cancer Epidemiol 2013;37:788-92.

16. Upadhyay RP, Misra P, Chellaiyan VG, et al. Burden of diabetes mellitus and prediabetes in tribal population of India: a systematic review. Diabetes Res Clin Pract 2013;102:1-7.

17. Lopez JM, Bailey RA, Rupnow MF, et al. Characterization of type 2 diabetes mellitus burden by age and ethnic groups based on a nationwide survey. Clin Ther 2014;36:494-506.

18. Trosko JE, Chang CC. An integrative hypothesis linking cancer, diabetes and atherosclerosis: the role of mutations and epigenetic changes. Med Hypotheses 1980;6:455-68.

19. Zoncu R, Efeyan A, Sabatini DM. mTOR: from growth signal integration to cancer, diabetes and ageing. Nat Rev Mol Cell Biol 2011;12:21-35.

20. Sabatino SA, Thompson TD, Wu XC, et al. The influence of diabetes severity on receipt of guideline-concordant treatment for breast cancer. Breast Cancer Res Treat 2014;146:199-209.

21. Liao S, Li J, Wei W, et al. Association between diabetes mellitus and breast cancer risk: a meta-analysis of the literature. Asian Pac J Cancer Prev 2011;12:1061-5.

22. Moore MA, Park CB, Tsuda H. Implications of the hyperinsulinaemia-diabetes-cancer link for preventive efforts. Eur J Cancer Prev 1998;7:89-107.

23. He X, Pu C, Quan Y, et al. Circular RNA HIPK3: an emerging player in diabetes. Transl Cancer Res 2018;7:S715-7.

24. Burroughs KD, Dunn SE, Barrett JC, et al. Insulin-like growth factor-I: a key regulator of human cancer risk? J Natl Cancer Inst 1999;91:579-81.

25. Breyer J. Does diabetes mellitus play an independent prognostic role in kidney cancer? Ann Transl Med 2019;7:S382.

26. Nakamura K, Wada K, Tamai Y, et al. Diabetes mellitus and risk of cancer in Takayama: a population-based prospective cohort study in Japan. Cancer Sci 2013;104:1362-7.

Cite this article as: Lu S, Wang A, Miao S, Zhang X, Jing S, Shan T, Guo Y, Liu Y. Association between type 2 diabetes and cancer incidence in China: data in hospitalized patients from 2006 to 2013. Ann Transl Med 2020;8(5):176. doi: 10.21037/ atm.2020.01.101 